\title{
Analysis of Rectangular EV Inductive Charging Coupler
}

\author{
Shuo Wang ${ }^{1}$, Student Member, IEEE, David G. Dorrell ${ }^{2}$, Senior Member, Youguang Guo ${ }^{1}$, Senior Member, IEEE, \\ ${ }^{1}$ University of Technology Sydney, Broadway, NSW 2007, Australia \\ ${ }^{2}$ University of KwaZulu-Natal, Howard College Campus, Durban 4041, South Africa
}

\begin{abstract}
The number of commercial electric vehicles has increased significantly in recent years. However, there are still limited recharging facilities for EVs. Wireless charging offers an alternative way to recharge with more flexibility and convenience. The wireless transformer/coupler is the key component in electric vehicle wireless charging. The maximum power transfer capability is limited by the coupler. In order to reach desired power transfer level, the parameters of the wireless transformer should be analyzed. The wireless power transfer system design also requires accurate coupler parameters. In this paper, rectangular pads with different size of ferrite bars were analyzed in finite element analysis software. The prototype was built to valid the simulation result.
\end{abstract}

Index Terms - Inductive charging, , medium frequency transformer, FEA, Coupler analysis

\section{INTRODUCTION}

$\mathrm{T}$ here is a great increase in the number of the vehicles on road in recent years and the total number is expected to reach the level of 2.5 billion in 2050 [1]. Although there is an improvement in the vehicle internal combustion engine efficiency, the greenhouse gas emission (GHG) from vehicles has been offset by the increased total travel of vehicles. About $40 \%$ of the growth in carbon dioxide (CO2) emissions from all energy-using sectors is produced by the transportation since 1990. Reducing the GHG emission from vehicles is becoming a serious issue, as GHG is a major factor in climate changes.

In recent years, the electric vehicle (EV) and hybrid electric vehicle (HEV) has regained the attention of researchers because they are considered better choice than internal combustion engines vehicles in reducing the GHG, especially in urban area. The EV and HEV produce no GHG emission on road. Vehicles that travel fewer than $50 \mathrm{~km}$ per day, which is within the range of using on board battery only, are responsible for more than $60 \%$ of daily passenger vehicle $\mathrm{km} \mathrm{[2],} \mathrm{so} \mathrm{using} \mathrm{electricity} \mathrm{to}$ power the vehicles would dramatically shift the GHG emissions and criteria pollutants from distributed vehicle tailpipes to large centralized power plants which could produce less GHG emission while generating the same amount of energy for its high efficiency. The assessment has proved that the greenhouse gas emission from plug-in electric vehicles reduces the GHG emissions by $32 \%$ compared to conventional vehicles.

Although the HEV and EV could reduce the GHG emission, they are still not widely accepted by the consumers due to the limitation of the price and the driving range, especially for the latter.

There are several ways to extend the EV driving range, and more on board battery cells is one of them. Extra battery cells increase the total possible energy on board. Therefore, the driving range of EV would be longer. On the other hand, however, extra battery also means more weight and volume for the on board energy storage. And as energy density of battery is still low compared to gasoline, the energy storage system would have a significant increase in weight and volume. The range/cells ratio also would decrease after the battery on board reaches certain limit.

At the same time the cost of the on board energy storage would increases if extra battery is added. The price for the EV battery is a serious issue. The raw materials are expensive, and even with mass production, the price might not show a significant decrease in the future. [3]. Expensive energy storage would lead to high cost for production as well as market price of EV.

Another reason for "range anxiety" is the time for EV to "refill the tank". High energy density batteries are used for EV applications, such as the lithium-ion battery cells in Tesla sports car, but recharging time is still relatively long compared to refilling a gasoline tank. For Tesla sports car, which is an EV, the $53 \mathrm{kWh}$ on board battery storage requires approximately 7 hours to charge using a 240 volt, 40 -amp outlet, and 4.5 hours using 240 volts, 70 -amp outlet. The Prius Plug-in Hybrid with $4.4 \mathrm{kWh}$ battery capacity will take 1.5 hours with 240 volts' outlet [4]. The recharging power of the battery is limited, in order to protect the battery and reach a longer life cycle. Although supercapacitors are introduced to overcome the battery disadvantage in power ratio, the fast recharging is only for short distance/ emergency recharging. The energy density and power density issues are still not solved for long distance drive over the EV driving range. Therefore, it is necessary to have more charging opportunities for EV.

With the development of battery and battery management technology, the range of several commercial EV reached over $300 \mathrm{~km}$ once fully recharged. Vehicle uptake is still limited due to "range anxiety" and also as a result of the long recharging time required for plug-in recharging. Compared to gasoline, one of the major advantages of electricity is its transmission method. The electricity is transferred over long distances, continually, through power cables. The energy can also be generated from clean and renewable sources. By installing recharging facilities in various domestic and public locations, there are more recharging opportunities. This infrastructure still is still in development and limited. Wireless charging offers an alternative option, which has the potential to recharge EVs. This can be done for short periods of time without the need for connection and even done when moving.

For EV wireless charging, the goal is to transfer sufficient power with highest efficiency possible to the EV to recharge. There are several key research areas in EV wireless charging: 1) charging pad design and optimization; 2) high frequency 
(HF) power electronics (PE) inverter and compensation circuit design; 3) system control; and 4) auto-alignment.

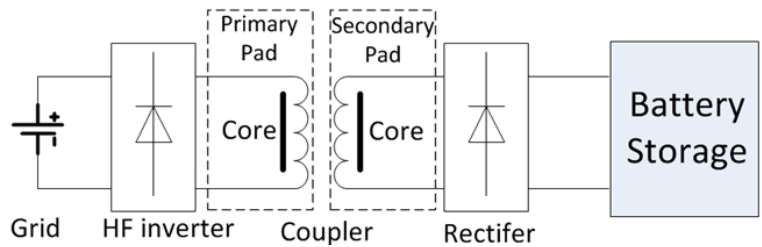

Fig. 1. Series-Series connected IPT system

The typical structure of a inductive charging system is shown in Fig. 1. The power from grid is converted to high frequency(HF) AC power by the HF inverter. Then the power is transferred across the airgap through a wireless transformer, followed by a rectifier.

From the literature, the operating frequency of the high frequency inverter ranges from $10 \mathrm{kHz}$ to several tens of $\mathrm{MHz}$. For high power inductive charging applications, such as EV wireless recharging, the maximum efficiency is sought in order to reduce the recharging cost. The switching loss at high frequency is one of the major loss for inductive charging system. With the development of $\mathrm{SiC}$ and $\mathrm{GaN}$ devices in recent years, > $100 \mathrm{kHz}$ inverters, which have low losses, are available for wireless charging applications. For low power applications such as implanted biomedical devices, the impedance matching method is used to reach maximum power transfer capability [5].

\section{INDUCTIVE CHARGING SYSTEMS}

For EV wireless charging transformer design, two coils or four coils structure are the most employed. In [6]-[11], two coil circular pads, I pads, DD pads, and DDQ pads, were proposed. Circular pads have the same misalignment tolerance in all directions, while the DD and I pads have more misalignment tolerance in the forward and reverse directions. The airgap is relatively large compare to power transformer, and the coupling coefficient is low. In many low power applications, four coil structure are used with impedance matching.

\section{A. Two winding structure}

The two coil system is widely used in EV inductive charging applications. Fig. 2 shows the equivalent circuit, where L1 and L2 are the inductances of the primary and secondary windings; $\mathrm{C} 1$ and $\mathrm{C} 2$ are the compensation capacitors and series-series (SS) capacitor compensation is used here; R1 and R2 are the total parasitic resistances of the windings and capacitors, and Rload is the load for the wireless charging system, respectively.

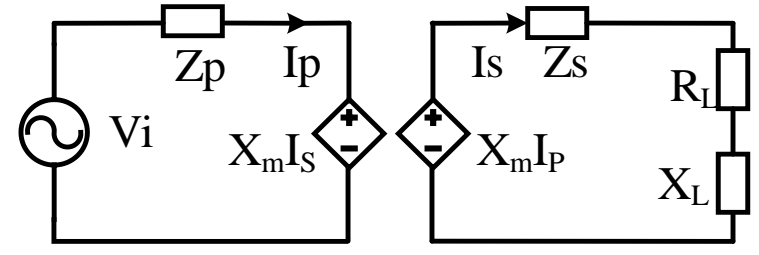

Fig. 2. Circuit model using equivalent source for coupler windings Lp and Ls.

The equivalent model of an SS compensated IPT system is shown in Fig. 2. where Vi is the input voltage of HF power source, and the angle frequency is $\omega$. The $\mathrm{Cp}$ and $\mathrm{Cs}$ are the compensation capacitors of primary and secondary sides respectively. The $\mathrm{Lp}$ is the primary winding inductance and the
Ls is the secondary winding inductance. The $\mathrm{M}$ is the mutual inductance between the primary and secondary windings. The $\mathrm{RL}$ and the $\mathrm{XL}$ are the load equivalent resistance and impedance. $\mathrm{Rp}$ and $\mathrm{Rs}$ are the winding resistances.

\section{B. Circuit Analysis}

The impedances of primary side, secondary side, and load are defined as

$$
\begin{gathered}
\mathrm{Z}_{\mathrm{p}}=\mathrm{j}\left(\omega \mathrm{L}_{\mathrm{p}}-\frac{1}{\omega \mathrm{C}_{\mathrm{p}}}\right)+\mathrm{R}_{\mathrm{p}} \\
Z_{S}=j\left(\omega L_{S}-\frac{1}{\omega C_{S}}\right)+R_{S} \\
Z_{L}=j\left(\omega L_{L}-\frac{1}{\omega C_{L}}\right)+R_{L}
\end{gathered}
$$

The secondary side impedance is

$$
Z_{22}=Z_{S}+Z_{L}
$$

And the mutual impedance is

$$
\begin{gathered}
X_{m}=j \omega M \\
\mathrm{P}_{\text {in }}\left(\mathrm{R}_{\mathrm{L}}, \mathrm{X}_{\mathrm{L}}\right)=\frac{\mathrm{V}_{\mathrm{in}}^{2}\left[\mathrm{R}_{\mathrm{p}}+\operatorname{Re}\left\{\mathrm{Z}_{\mathrm{r}}\right\}\right]}{\left[\mathrm{R}_{\mathrm{p}}+\operatorname{Re}\left\{\mathrm{Z}_{\mathrm{r}}\right\}\right]^{2}+\left[\mathrm{X}_{\mathrm{p}}+\operatorname{Im}\left\{\mathrm{Z}_{\mathrm{r}}\right\}\right]^{2}}
\end{gathered}
$$

The circuit model could be equivalent to the circuit in Fig. 2 . The reflected impedance from secondary side to primary side is

$$
Z_{21}=\frac{X_{m}^{2}}{Z_{22}}
$$

Therefore, the currents of primary side and secondary side are

$$
\begin{gathered}
I_{p}=\frac{V_{i}}{Z_{p}+Z_{21}} \\
I_{s}=\frac{j \omega M I_{p}}{Z_{s}+Z_{L}}
\end{gathered}
$$

From the equivalent circuit, the input power from the HF power sources is,

$$
P_{\text {in }}\left(R_{L}, X_{L}\right)=\frac{V_{i}^{2}\left[R_{p}+R e\left(Z_{21}\right)\right]}{\left(Z_{p}+Z_{21}\right)^{2}}
$$

The real power received by the load is,

where

$$
\begin{aligned}
P_{\text {out }}\left(R_{L}, X_{L}\right) & =\frac{X_{m}^{2} V_{i}^{2} R_{L}}{Z_{c}}=\frac{(\omega M)^{2} V_{i}^{2} R_{L}}{Z_{c}} \\
& =\frac{\omega^{2} V_{i}^{2} k^{2} L_{1} L_{2} R_{L}}{Z_{c}}
\end{aligned}
$$

$$
Z_{c}=\left(Z_{p}+Z_{21}\right)^{2}\left(Z_{s}+Z_{L}\right)^{2}
$$

The system efficiency is

$$
\eta=\frac{P_{\text {out }}}{P_{\text {In }}}
$$

The system performance could be evaluated using the above equations. However, the system performances, such as the input power, output power and system efficiency, rely on the coupler parameters, including the coupling coefficient $k$, the primary and secondary inductances $L_{1}$ and $L_{2}$, and the resistances. Without careful determination of these parameters, the system modelling would be inaccurate. Therefore, coupler pad analysis is essential.

\section{ReCtangular Pad Simulation}

The coupler is the key element for wireless power transfer system. For EV wireless charging transformer, the ferrite bars are used as the core instead of ferrite plate. The major consideration for using ferrite bar is tradeoff between the power 
transfer efficiency and the on board weight of the wireless charger. In order to investigate the influence of the ferrite bars in power transfer capability, the coupling with different amount of ferrite materials should be analyzed.

As the geometry of rectangular pad with ferrite bars is a 3D geometry problem with limited symmetry, it is difficult to build an analytical model. The finite element analysis (FEA) is widely used in solving geometry problems. In this part, a rectangular pad with different ferrite bars are simulated in FEA software ANSYS MAXWELL.

\section{A. Simulation model with $186 \mathrm{~mm}$ ferrite bars on both sides}

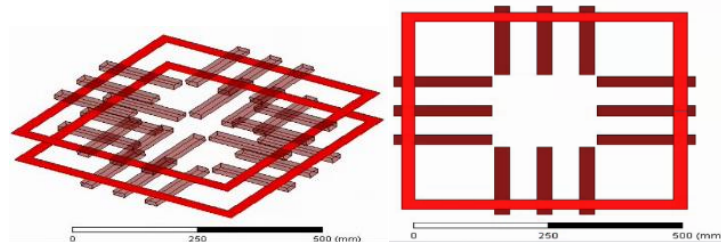

Fig. 3. Simulation model of rectangular pad: a) coupler model side view, b) top view of primary side coupler.

The rectangular pad model is shown in Fig.3. The parameters of the pad is shown in Table. I. EPCOS N87 ferrite is chosen as the core material. The size of the ferrite bar is $186 * 28 * 16 \mathrm{~mm}$. For the primary side, a total number of 12 ferrite bars are used. The inner side of the ferrite bar is $100 \mathrm{~mm}$ from the central point, and the ferrite bars on each side of the rectangular winding is $80 \mathrm{~mm}$ away from the bar in the central of that side. The Litz-wire diameter is set to $2.5 \mathrm{~mm}$, and each winding width has 10 turns, therefore the total winding width is $25 \mathrm{~mm}$. The inner side of the winding is $245 \mathrm{~mm}$ from the central point. The outer side of the ferrite is $572 \mathrm{~mm}$.

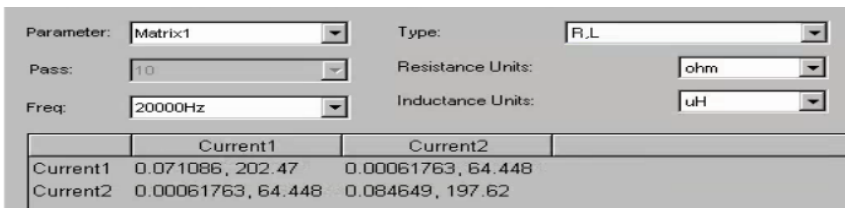

Fig. 4 Self-inductances of primary and secondary windings and mutual inductance with $186 \mathrm{~mm}$ ferrite bar on both sides

Table 1. Rectangular Pad Parameters

\begin{tabular}{|l|l|}
\hline & Size \\
\hline Coupler & $572 * 572 \mathrm{~mm} 2$ \\
\hline Winding (10 turns) & $2.5 \mathrm{~mm}$ \\
\hline Ferrite (12 piece each side) & $186 * 28 * 16 \mathrm{~mm}$ \\
\hline
\end{tabular}

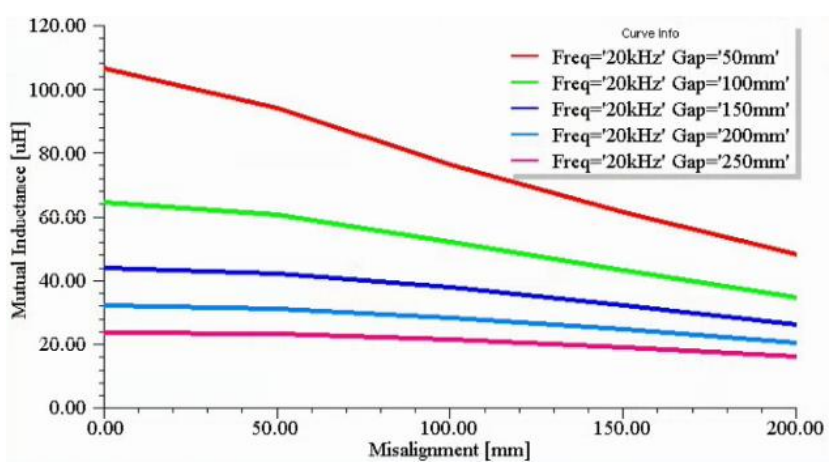

Fig. 5. Mutual inductance versus misalignment with $186 \mathrm{~mm}$ ferrite bar on both sides

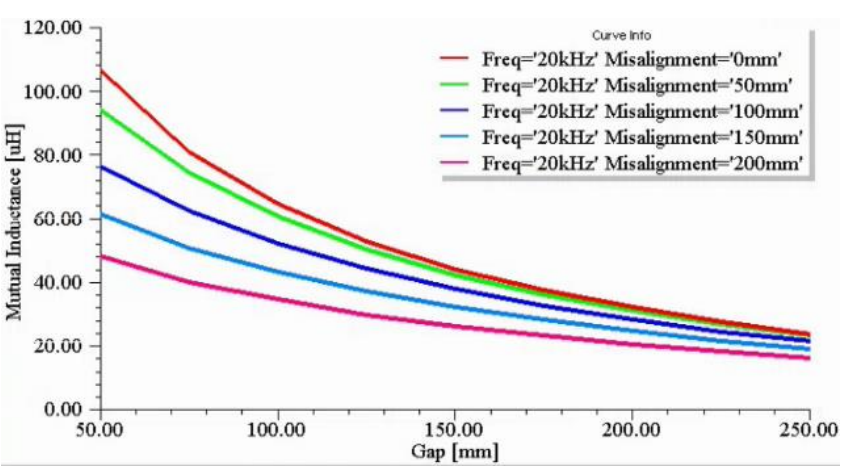

Fig. 3.1. Mutual inductance versus air bap distance with $186 \mathrm{~mm}$ ferrite bar on both sides

The mutual inductances between the primary and secondary windings are simulated with different airgaps and misalignment distances. Fig.4 shows simulated results. The resistance and inductance are shown in each cell. The Current1/Current 1 cell shows the primary side resistance and self-inductance. And Current $2 /$ Current 2 cell shows the secondary side resistance and self-inductance. The Current1/Current2 and Current2/Current shows the mutual inductance therefore the values in these cells are the same. The resistance here is DC resistance as current is assumed to be distributed evenly. Fig.5 shows mutual inductance versus misalignment distance. The misalignment distance starts from 0 and ends at $200 \mathrm{~mm}$, which is from alignment to more than $1 / 3$ of the pad diameter.

Fig.5 shows mutual inductance versus airgap distance. Mutual inductance decreases with increasing airgap and misalignment. For the same distance, the decrease ratio of mutual inductance versus gap is higher than that of the misalignment. The coupling coefficient versus airgap distance and the misalignment is shown in Fig.6.

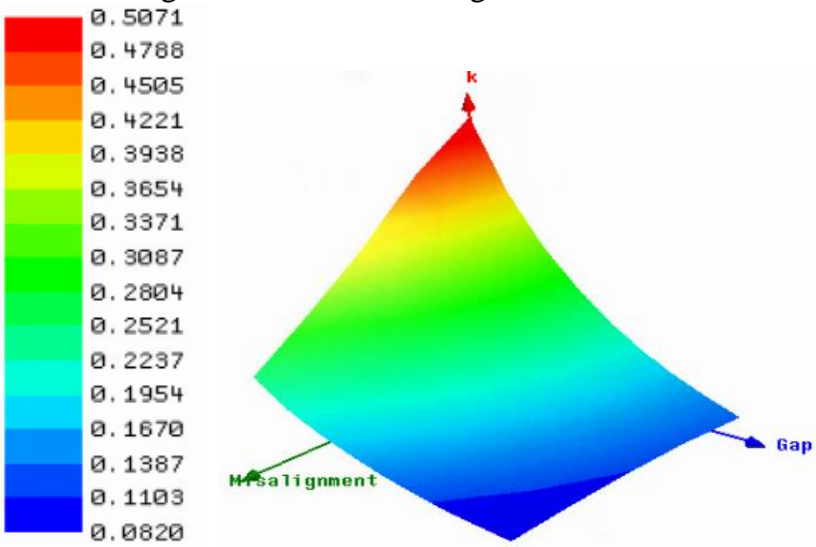

Fig. 6. Coupling coefficient versus misalignment and air gap distance with $186 \mathrm{~mm}$ ferrite bar on both sides

\section{B. Model: secondary side with $93 \mathrm{~mm}$ length ferrite bars}

The on board system prefers light weight and low component count devices. The density of the ferrite bar is $4850 \mathrm{~kg} / \mathrm{m} 3$, and the weight of a $93 * 28 * 16 \mathrm{~mm}$ ferrite bar is about $202 \mathrm{~g}$. In order to evaluate the reduced weight secondary pad, the secondary side uses $93 * 28 * 16 \mathrm{~mm}$ ferrite instead of the $186 * 28 * 16 \mathrm{~mm}$ ferrite bars in the previous simulation. The inner side of the ferrite bar is $193 \mathrm{~mm}$ from the central point. The primary side still uses the same size $186^{*} 28 * 16 \mathrm{~mm}$ ferrite bars. The simulation model is shown in Fig.7. 


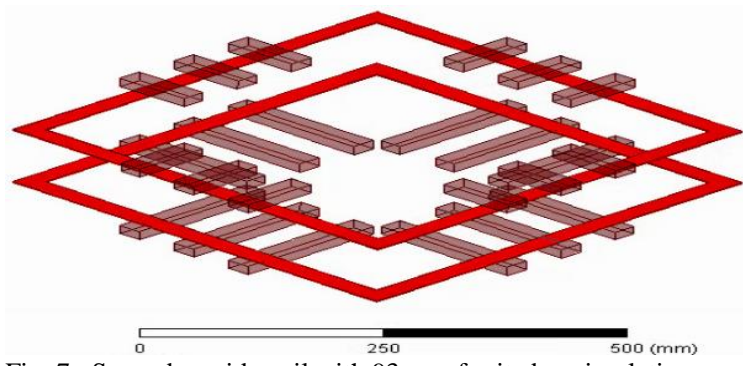

Fig. 7. Secondary side coil with $93 \mathrm{~mm}$ ferrite bar simulation

The simulated inductances of the primary and secondary windings are shown in Fig.8. The mutual inductance versus the airgap is shown in Fig.9, and the mutual inductance versus misalignment is shown in Fig.10. The coupling coefficient of primary and secondary windings is shown in Fig.11.

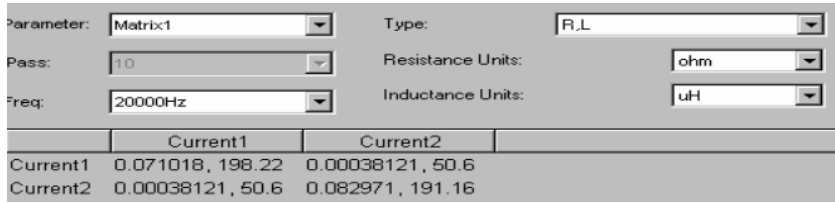

Fig. 8. Inductance of primary and secondary winding and mutual inductance with $93 \mathrm{~mm}$ ferrite bar on secondary side

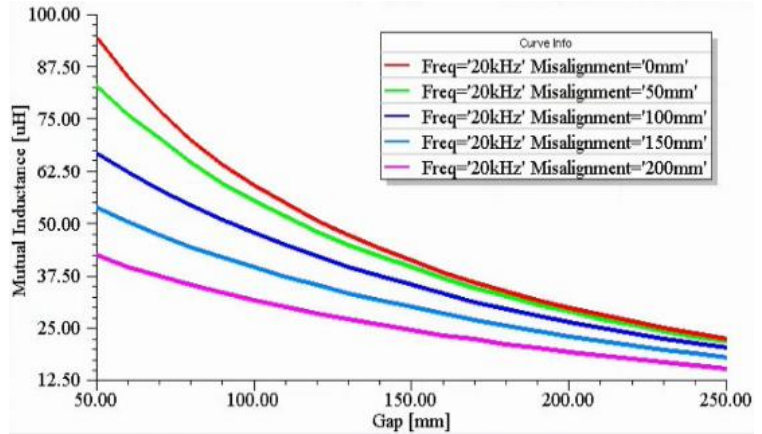

Fig.9. Mutual inductance versus air gap distance with $93 \mathrm{~mm}$ ferrite bar on secondary side

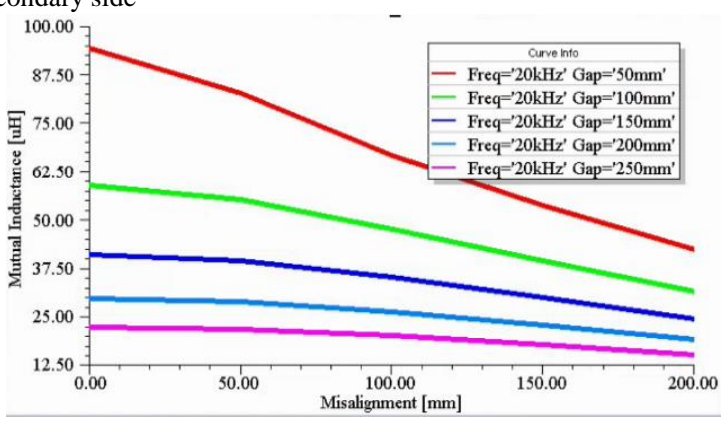

Fig. 10. Mutual inductance versus misalignment with $93 \mathrm{~mm}$ ferrite bar on secondary side

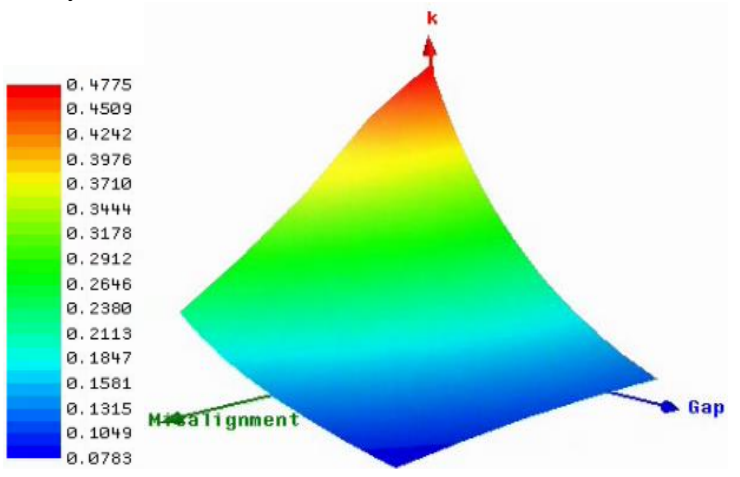

Fig. 11. Coupling coefficient versus misalignment and air gap distance with $93 \mathrm{~mm}$ ferrite bar on secondary side

\section{Secondary side coil only}

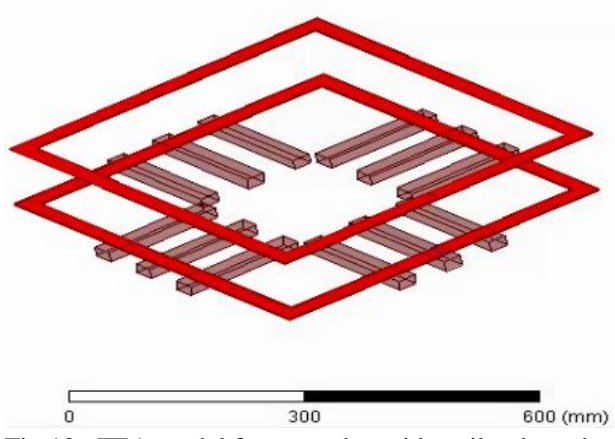

Fig.12. FEA model for secondary side coil only pad

The secondary side coil only coupler is simulated in this part as shown in Fig.12. The ferrite bars in the secondary side are removed. The primary side setup is the same as before.

The simulated inductances of the primary and secondary windings are shown in Fig.13. The mutual inductance versus airgap is shown in Fig.14, and the mutual inductance versus misalignment is shown in Fig. 15.

\begin{tabular}{|c|c|c|c|c|}
\hline Paranteter: & Matrix1 & Type: & R.L & \pm \\
\hline Pass: & 10 & Resistance Units: & & ohm \\
\hline Freq: & $20000 \mathrm{~Hz}$ & Inductance Units: & & uH \\
\hline & Current1 & Current2 & & \\
\hline Current1 & $0.070854,193.12$ & $9478 \mathrm{E}-20,50.012$ & & \\
\hline Current2 & $-5.9478 \mathrm{E}-20,50.012$ & $.070947,160.41$ & & \\
\hline
\end{tabular}

Fig. 13. Inductance of primary and secondary winding and mutual inductance of secondary side coil only pad

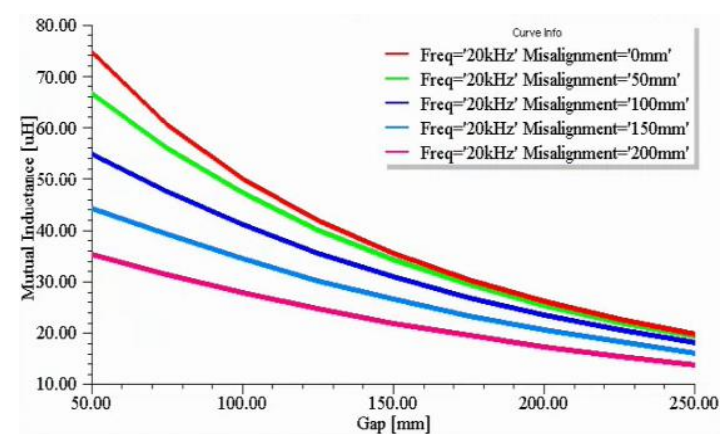

Fig. 14 Mutual inductance versus air gap distance with secondary side coil only pad.

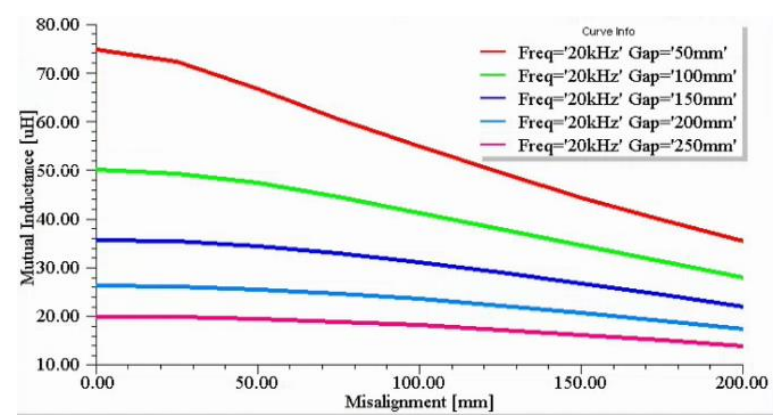

Fig. 15. Mutual inductance versus misalignment with secondary side coil only pad.

\section{Coil Only Pad}

For comparison to above pads, the coil only pad is simulated as shown in Fig.16. All the ferrite bars on both sides are 
removed.

The simulated inductance of the primary and secondary winding is shown in the Fig.17. The mutual inductance versus airgap is shown in Fig.18, and the mutual inductance versus misalignment is shown in Fig. 19.

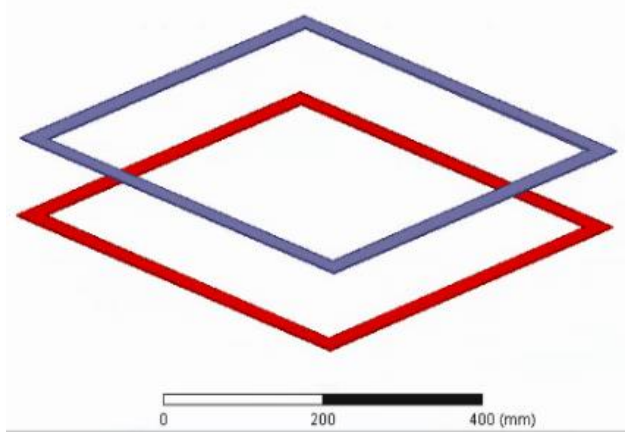

Fig. 16. FEA model for coil only pad.

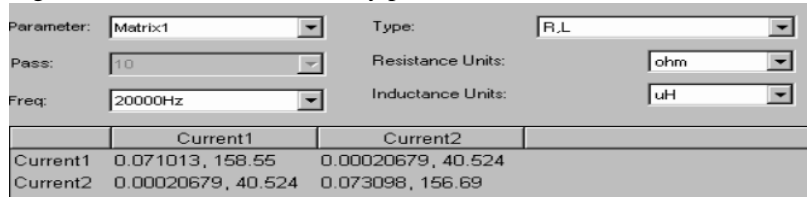

Fig. 17. Inductances of primary and secondary windings, and mutual inductance of coil only pad

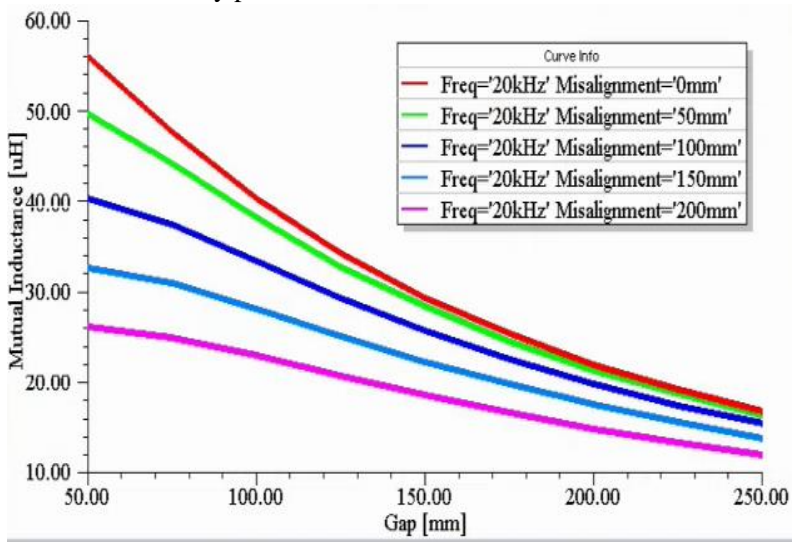

Fig.18 Mutual inductance versus air gap distance with coil only pad

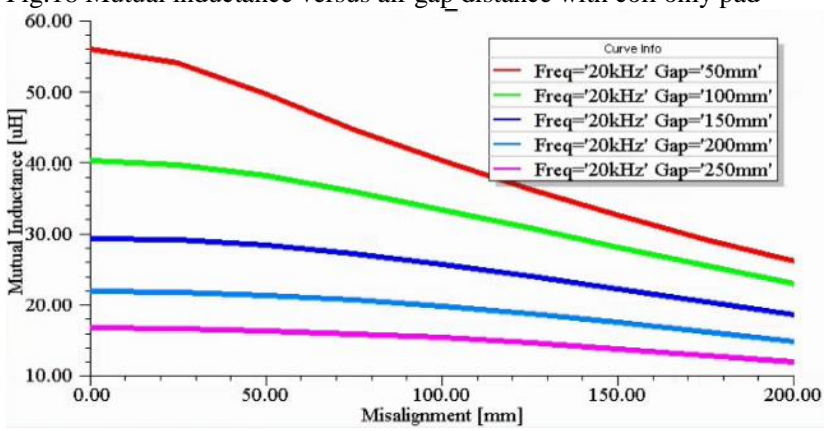

Fig.19. Mutual inductance versus misalignment with coil only pad.

\section{E. Comparison of Pads}

For the same primary pad, the mutual inductances between it and above four secondary side pads are shown in the Fig.20. Secondary side pad with more ferrite bars has higher mutual inductance with the primary side.

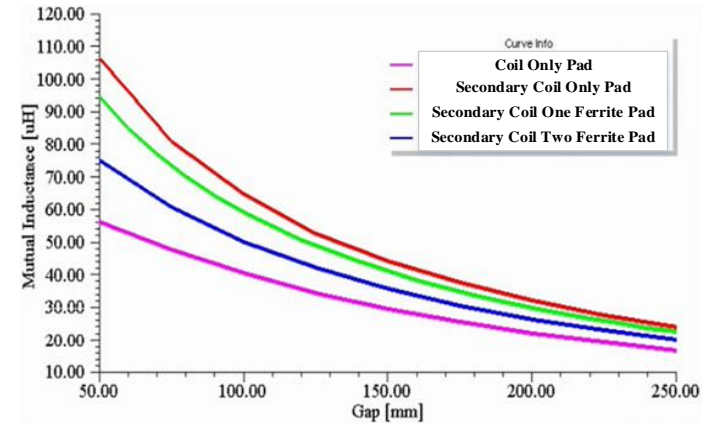

Fig. 20. Comparison of mutual inductance of different pads.

\section{EXPERIMENT VALIDATION}

The full scale transformer with the same parameters in Table. I is set up as shown in Fig.21. The primary side uses two $93 * 28 * 16 \mathrm{~mm}$ ferrite strips to form a $186 * 28 * 16 \mathrm{~mm}$ longer ferrite strip. The primary winding is wound in the slot on a wood board. The ferrite bars are buried in the wood board. The secondary side setup is symmetrical to the primary. The secondary side is held by two plastic holders on four wood rods. The Litz wire with $350 * 0.08 \mathrm{~mm}$ strands is used for winding. The airgap distance between the primary and secondary sides is in the range of $30 \mathrm{~mm}$ to $400 \mathrm{~mm}$.

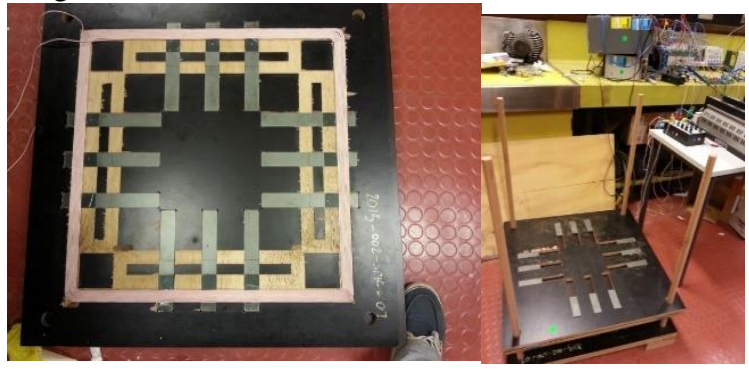

Fig. 21. Rectangular pad setup.

The inductance of the windings is measured using Keysight U1733C RLC meters. The primary winding and secondary winding are measured respectively. The self-inductance of the winding from simulation and experiment agrees well with each other. The simulated and measured self-inductance is as shown in Table II.

TABLE II. INDUCTANCE FROM EXPERIMENT AND SIMULATION

\begin{tabular}{l|c|c}
\hline \hline & Simulation & Experiment \\
\hline $\begin{array}{l}\text { Coil only without } \\
\text { ferrite }\end{array}$ & $157.37 \mu \mathrm{H}$ & $157.61 \mathrm{uH}$ \\
\hline $\begin{array}{l}\text { Primary Winding } \\
\text { with two Ferrite Bars }\end{array}$ & $197.52 \mathrm{uH}$ & $198.5 \mathrm{uH}$ \\
\hline $\begin{array}{l}\text { Secondary Winding } \\
\text { with one Ferrite Bar }\end{array}$ & $188.95 \mathrm{uH}$ & $192.4 \mathrm{uH}$ \\
\hline \hline
\end{tabular}

The mutual inductance is measured using aiding method. The aiding method coupling coefficient is shown as

$$
\mathrm{k}_{\text {aid }}(z)=\left.\frac{L_{\text {aid }}-\left(L_{1}+L_{2}\right)}{2 \sqrt{L_{1} L_{2}}}\right|_{z}
$$

where L1 and L2 are the primary and secondary winding inductances, Laid is the measured inductance with L1 and L2 
are series connected at certain airgap.

For the pad with $93 * 28 * 16 \mathrm{~mm}$ ferrite bars, the measured aiding inductance and calculated coupling coefficient $\mathrm{k}$ are listed in Table III.

\begin{tabular}{cll} 
TABLE III. MEASURED LAID AND CALCULATED K WITH SPACING \\
\hline Airgap & Laidu(H) & $\mathrm{k}$ \\
\hline 50 & 529.3 & 0.4776 \\
100 & 462.3 & 0.2898 \\
150 & 430.5 & 0.2 \\
200 & 412 & 0.1489 \\
250 & 400 & 0.115 \\
\hline
\end{tabular}

The experiment and simulation results of the coupling coefficient for secondary sides with half ferrite bars are shown in Fig.22. The coupling coefficients of the simulation and experiment agree well with a large airgap between windings. With smaller airgap, the results have a difference. This is because that in the experiment, the secondary side is held by two wooden rods and there is error in the measured distance. As mutual inductance has a higher increasing ratio to the distance, the error causes a significant measurement error in the coupling coefficient. This error could be removed by using a shelf type stand to hold the secondary side.

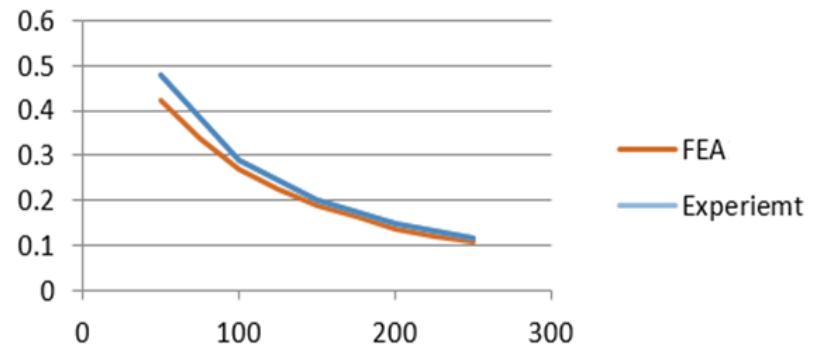

Fig. 22. Experiment and FEA results of coupling coefficient $\mathrm{k}$

\section{CONCLUSION}

The wireless charging offers an alternative way to recharge the EV. It could be fully automation as there is no manual connection required in wireless charging. The wireless transformer is the key element in the system. A rectangular pad has been analyzed in FEA in this paper. The pads with different ferrite bars are simulated and compared. The length of the ferrite bar would increase coupling coefficient and mutual inductance between primary and secondary side. Therefore, the power transfer capability with longer ferrite bar could transfer more power than those with shorter ferrite. The experiment has been done to valid the simulation results. The experiment shows that the simulation is accurate for inductive power transfer pad design.

\section{REFERENCES}

[1] OECD and I. T. Forum., ITF Transport Outlook 2015: OECD Publishing. DOI: http://dx.doi.org/10.1787/9789282107782-en.

[2] C. Samaras and K. Meisterling, "Life Cycle Assessment of Greenhouse Gas Emissions from Plug-in Hybrid Vehicles: Implications for Policy," Environmental Science \& Technology, vol. 42, pp. 3170-3176, 2008.

[3] S. Lukic, J. Cao, R. C. Bansal, F. Rodriguez and A. Emadi, "Energy storage systems for automotive applications", IEEE Trans. Ind. Electron., vol. 55, no. 6, pp. 2258-2267, Jun. 2008.
[4] M. Yilmaz and P. T. Krein, "Review of Battery Charger Topologies, Charging Power Levels, and Infrastructure for Plug-In Electric and Hybrid Vehicles," IEEE Trans. Power Electron., vol. 28, pp. 2151-2169, 2013.

[5] S. Y. R Hui, W. X. Zhong, C. K. Lee, "A critical review of recent progress in mid-range wireless power transfer," IEEE Trans. on Power Electron., 2013, DOI: 10.1109/TPEL.2013.2249670.

[6] W. Chwei-Sen, O. H. Stielau, and G. A. Covic, "Design considerations for a contactless electric vehicle battery charger," IEEE Trans. on Industrial Electronics, vol. 52, pp. 1308-1314, 2005.

[7] M. Budhia, J. T. Boys, G. A. Covic, and H. Chang-Yu, ""Development of a single-sided flux magnetic coupler for electric vehicle IPT charging systems," IEEE Trans. on Ind. Electr., vol. 60, pp. 318-328, 2013.

[8] S. Wang and D. G. Dorrell, "Loss analysis of circular wireless EV charging coupler," IEEE Trans. on Magn., vol. 50, no. 11, Article\#: 8402104, 2014.

[9] S. Wang and D. G. Dorrell, "Review of wireless charging coupler for electric vehicles," IEEE IECON Conference, Vienna, Nov 2013.

[10] F. Musavi, M. Edington, and W. Eberle, ""Wireless power transfer: A survey of EV battery charging technologies," IEEE ECCE, 2012, pp. 1804-1810.

[11] G. A. Covic, L. G. Kissin, D. Kacprzak, N. Clausen, and H. Hao, “A bipolar primary pad topology for EV stationary charging and highway power by inductive coupling," IEEE ECCE, Sep. 2011, pp. 1832-1838. 